\title{
Appropriate lung cancer treatments: A missed opportunity ... or an opportunity to modify?
}

\author{
Stephen C. Yang, MD
}

From the Department of Surgery, The Johns Hopkins Medical Institutions, Baltimore, Md.

Disclosures: Author has nothing to disclose with regard to commercial support.

Received for publication Feb 26, 2016; accepted for publication Feb 27, 2016.

Address for reprints: Stephen C. Yang, MD, Department of Surgery, The Johns Hopkins Medical Institutions, 600

N Wolfe St, Blalock 240, Baltimore, MD 21287 (E-mail: syang@jhmi.edu).

J Thorac Cardiovasc Surg 2016;151:1559-60

$0022-5223 / \$ 36.00$

Copyright (C) 2016 Published by Elsevier Inc. on behalf of The American Association for Thoracic Surgery http://dx.doi.org/10.1016/j.jtcvs.2016.02.060

Given that this is the 21 st century, the paucity of resources available to help with the management of patients who have cancer is difficult to accept. The National Cancer Care Network has grown, and now is composed of 26 centers. On the Internet, an estimated $>150,000$ Web sites are related to the topic of lung cancer, including informational and social media links. Nearly every medical specialty has developed their own management guidelines. In 2015, one could attend a dedicated lung cancer meeting almost every week, somewhere in the world.

Despite these statistics, Bott and colleagues ${ }^{1}$ find that at least one third of patients who have clinical stage II nonsmall cell lung cancer (NSCLC) are offered either suboptimal or no treatments. The authors begin with the accepted premise that surgical resection should be offered to this population of patients. Their study, based on a 20,366-patient cohort, from the years 1998 to 2010, from the National Cancer Database, underscores the message that all patients should be evaluated by a surgeon to determine their candidacy for resection.

As with any surprising findings, several points surface: Are the results an accurate reflection of treatment, and if so, how can this be explained? Given that published "standards" are available for lung cancer care, why are surgeons not following them? What can we do to better ensure appropriate treatment for all?

Disparities in surgical resection for lung cancer have been studied extensively. In 1999, in what may be the initial study of such disparities, Bach and colleagues ${ }^{2}$ showed that African Americans were not offered surgical resection as often as Caucasians were $(64 \%$ vs $77 \%, P<.001)$. This difference translated into a significantly lower 5-year survival. Farjah and colleagues, ${ }^{3}$ in 2009 , reported a marginally higher refusal rate for surgery by African American patients and proposed factors such as cultural beliefs, distrust, and limited access to subspecialty care as driving forces.

Cykert and colleagues, ${ }^{4}$ in 2010 , reinforced this finding with results from a prospective survey of 386 patients who had early-stage NSCLC, in 5 communities. Again noted was a significant difference in surgical resection rates

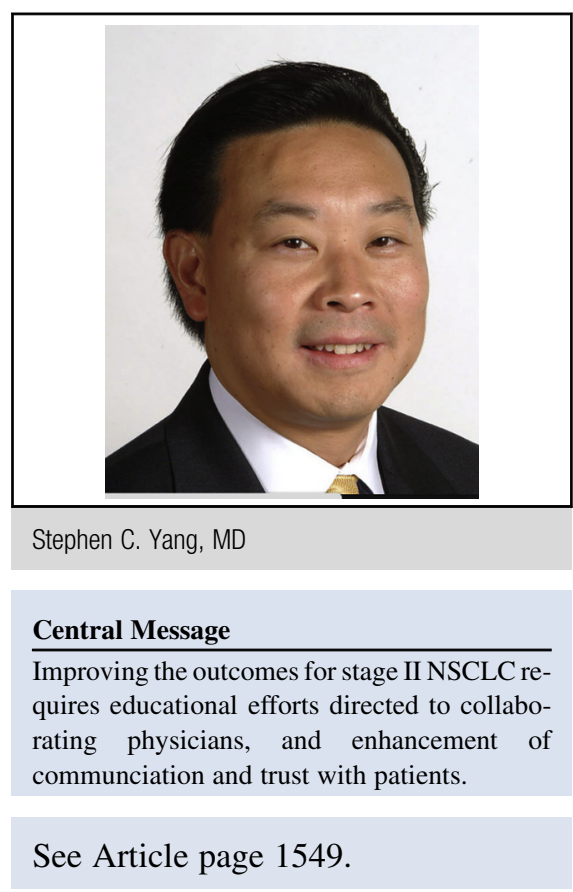

for stage I and II NSCLC between African Americans and Caucasians $(63 \%$ vs $75 \%, P=.03)$. This same pattern has been shown in Hispanic (vs Caucasian) patients, in a 2005 report by Wisnivesky and colleagues, ${ }^{5}$ correlating a lower rate of surgical resection with survival.

Several factors can account for these findings, many of which were suggested by Bott and colleagues ${ }^{1}$ in their current work: age; poor access to appropriate health care; community-based practices; lower economic background; deficiency in understanding Internet-based information; lack of responsibility for one's own health issues; and cultural differences between nonblack physicians and nonwhite patients. We hope these factors can be reversed with enhancement of education and information access.

However, the issue of universal health insurance will not necessarily bridge this educational gap in appropriate cancer care. In the 2010 study of Cykert and colleagues, although $90 \%$ of the study population had health insurance, nearly $20 \%$ lacked a regular source of care, and the underserved in this predicament received cancer surgery less often than did Caucasians. Universal access to care seems to be a reasonable approach to eliminating such disparities in lung cancer survival, even when patients have insurance, this does not create such an equivalency.

Bott and colleagues ${ }^{1}$ ask the rhetorical question: Is this a missed treatment opportunity? Although this question is not 
specifically addressed, and doing so is not a goal of the study, the ability to educate the health care practitioners dealing with early stages of NSCLC may be an important factor. In 1998, Perez ${ }^{6}$ published a telephone survey with 100 primary care physicians and 250 specialists (pulmonary, medical/radiation oncology, and thoracic surgery) about care at various stages of NSCLC. Although $>90 \%$ agreed that surgery was appropriate for treating stage I disease, the percentage selecting surgery was lower in each specialty (14\%-57\%). Although surgery remained the most recommended treatment option, the range of opinions was broad regarding the addition of radiation or chemotherapy. A notably higher proportion of radiation oncologists recommend radiation in addition to surgery for stage II disease, and very few primary care physicians recommend surgery.

Perhaps the "missed opportunity" lies in the misperception of the prognosis of NSCLC and the era physicians were trained. A survey of 971 members of the American College of Chest Physicians was conducted by Schroen and colleagues ${ }^{7}$ in 2000 . Ten percent of thoracic surgeons, and $22 \%$ of pulmonologists, underestimated the 5-year survival rates, and these physicians saw fewer lung cancer patients and practiced in nonacademic environments. Thus, the perception of a poor overall survival translated into fewer surgery recommendations and less familiarity with current treatment algorithms.

A more recent report on health care disparities adds to the equation the influence of insurance status on the outcome of stage I/II NSCLC. Shi and colleagues ${ }^{8}$ analyzed nearly 300,000 patients from the NCNB, from the period 1998 to 2011, about the same time frame as the report by Bott and colleagues. ${ }^{1}$ The median overall survival was $2.90,3.42$, 3.86, 4.19, and 6.23 years for Medicare, Medicaid, uninsured, unknown, and privately insured patients, respectively, with the highest mortality rates for those who had Medicaid and the uninsured. Ironically, given that in the age range in which most patients have NSCLC is that in which they are likely to have Medicare, their outcomes nonetheless seem the poorest. Perhaps insurance status in part mediates the treatment algorithm, and thus affects cancer survival.

Collectively, these findings suggest that we as surgeons must drive educational efforts and appropriate treatment algorithms for all patients who have this and other devastating diseases. Despite the plethora of information available in print, via seminars, and on the Internet, nothing can replace the trust of a patient in their physician for providing current treatment options associated with optimal outcomes. We should concentrate on improving communication between clinicians and patients of all races and backgrounds, and ensure that a minimum standard is directed at those communities and physicians who lack experience in dealing with lung cancer. We hope the authors will repeat this study in a few years to assess the impact of these instructional strategies.

\section{References}

1. Bott MJ, Aalok PP, Verma V, Crabtree TD, Morgensztern D, Robinson CG, et al. Patterns of care in hilar node-positive (N1) non-small cell lung cancer: a missed treatment opportunity? J Thorac Cardiovasc Surg. 2016;151:1549-58.

2. Bach PB, Cramer LD, Warren JL, Begg CB. Racial differences in the treatment of early-stage lung cancer. N Engl J Med. 1999;34:1198-205.

3. Farjah F, Wood DE, Yanez ND III, Vaughan TL, Symons RG, Krishnadasan B, et al. Racial disparities among patients with lung cancer who were recommended operative therapy. Arch Surg. 2009;1441:14-8.

4. Cykert S, Dilworth-Anderson P, Monroe MH, Walker P, McGuire FR, CorbieSmith G, et al. Factors associated with decisions to undergo surgery among patients with newly diagnosed early-stage lung cancer. JAMA. 2010;303:2368-76.

5. Wisnivesky JP, McGinn T, Henschke C, Hebert P, Iannuzzi MC, Halm EA. Ethnic disparities in the treatment of stage I non-small cell lung cancer. Am J Respir Crit Care Med. 2005;17:1158-63.

6. Perez EA. Perceptions of prognosis, treatment, and treatment impact on prognosis of non-small cell lung cancer. Chest. 1998;1142:593-604.

7. Schroen AT, Detterbeck FC, Crawford R, Rivera MP, Socinski MA. Beliefs among pulmonologists and thoracic surgeons in the therapeutic approach to non-small cell lung cancer. Chest. 2000;1181:129-37.

8. Shi R, Diaz R, Shi Z, Duvall E, Mills G. The effect of payer status on survival of patients with stage I/II non-small cell lung cancer: NCDB 1998-2011. Anticancer Res. 2016;36:319-26. 